\title{
Migration, Sex Bias, and Child Growth in Rural Pakistan
}

\author{
Ghazala Mansuri*
}

\begin{abstract}
Temporary economic migration is undertaken largely in response to resource constraints. This is evident in the volume of remittances sent back by migrants to their families of origin. In agricultural settings, where those left behind are likely to face considerable exposure to uninsured income risk, such resource flows should translate into better risk bearing capacity. In this paper we take up this question by asking whether economic migration allows households to avoid costly risk coping strategies. We focus on early child growth since there is considerable epidemiological evidence that very young children are particularly vulnerable to shocks that lead to growth faltering, with substantial long-term health consequences. The data come from rural Pakistan, where, as in the rest of Asia, son preference is substantial and there are large gender gaps in most developmental outcomes. As such, our interest is in examining also whether migration induced resource flows allow households to extend better nutrition and health care protection to girls. Recent work on the intra-household allocation of resources and risk has also shown that gender differences in the relative burden of risk may be important and that the allocation of resources to daughters is often one margin along which poor households adjust to uninsurable transitory income shocks. After accounting for selection into migration, the results indicate that migration has a substantially larger positive impact on growth outcomes for young girls. Moreover, the growth advantage is sustained among older girls, suggesting potential intergenerational benefits of averting nutritional and other health shocks for girls in early childhood. These results are further validated by restricting the sample to migrant households and comparing the growth outcomes of siblings before and after migration.
\end{abstract}

Keywords: Migration, Child Growth, Vulnerability, Sex-Bias

World Bank Policy Research Working Paper 3946, June 2006

The Policy Research Working Paper Series disseminates the findings of work in progress to encourage the exchange of ideas about development issues. An objective of the series is to get the findings out quickly, even if the presentations are less than fully polished. The papers carry the names of the authors and should be cited accordingly. The findings, interpretations, and conclusions expressed in this paper are entirely those of the authors. They do not necessarily represent the view of the World Bank, its Executive Directors, or the countries they represent. Policy Research Working Papers are available online at http://econ.worldbank.org. 


\section{Introduction}

Temporary economic migration is undertaken in large part by relatively low skilled households as a mechanism to diversify income risk and reduce resource constraints. ${ }^{1}$ This aspect of the migration decision is evident in the sheer volume of remittances sent back by migrants to their families of origin. In agricultural settings, where households face considerable exposure to uninsured income risk and often undertake costly strategies to avert or cope with such risk, ${ }^{2}$ such migration induced resource flows should translate into better risk bearing capacity for those left behind.

In this paper we take up this question by asking whether economic migration allows households in sending communities to avoid costly risk coping strategies. We focus on early child growth since there is considerable epidemiological evidence that very young children are particularly vulnerable to shocks that lead to growth faltering, with substantial longterm health consequences. ${ }^{3}$

Recent work on the intra-household allocation of resources and risk has also shown that gender differences in the relative burden of risk may be important, ${ }^{4}$ and that the allocation of resources to daughters is often one margin along which poor households adjust to uninsurable transitory income shocks. ${ }^{56}$ This suggests that the opportunity to migrate would confer special benefits to girls in origin households. In particular, risk sensitive outcomes for girls in migrant households should improve to a disproportionate degree, as compared to boys, in the same households. Specifically, it suggests that the difference in growth outcomes for girls in migrant households, as compared to their counterparts

\footnotetext{
${ }^{1}$ Migration reduces risk by allowing some household members to move into a sector or market where earnings are either negatively correlated or orthogonal to earnings in the local economy. Both the migrant and the family left behind clearly stand to gain from this risk-sharing. See Stark and Levhari (1982) and Stark and Bloom (1985) for early work on this.

${ }^{2}$ See, for example, Townsend(1995), Morduch(1995), Udry (1990), Fafchamps Udry and Czukas (1998), Kochar (1998) and Jacoby and Skoufias (1997).

${ }^{3}$ Martorell ((1995), (1999)) and Martorell et. al. (1994), for example, have shown that stature by age three is strongly correlated with attained body size in adulthood. Indeed, it appears that from age 3 onwards children, even from very poor families, basically grow at the same rate as children in developed economies. The long term consequences of nutritional shocks at a young age are thus likely to be very substantial.

${ }^{4}$ Hoddinott and Kinsey (2001), Foster(1995).

${ }^{5}$ Rose (1999), Dercon and Krishnan(2000), Das Gupta (1987), Rosenzweig and Schultz (1982), Behrman (1988), and Behrman and Deolalikar(1990).

${ }^{6}$ There is some evidence on morbidity and health facility usage in Pakistan that is consistent with this. The World Bank's Country Gender Assessment for Pakistan (2005) shows that girls in poorer households are significantly less likely to use health care facilities than boys in the same households, using nationally representative data (the Pakistan Integrated Household Survey (2001)).
} 
in households who do not have the opportunity to undertake migration, should be larger than this same difference for boys.

This issue is of great salience in the context we study since rural Pakistan, like much of the rest of Asia, is characterized by significant son preference and there are large gender gaps in most developmental outcomes. As such, our interest is in examining also whether migration induced resource flows allow households to extend better nutrition and health care protection to girls.

The paper thus brings together the literature on intra-household resource allocation under risk, and in particular, potential gender bias in risk bearing within households, with the literature on the impact of migration on household welfare.

Few papers have examined the consequences of migration for the gender allocation of resources and risk among children. This is perhaps largely due to the absence of adequate data and in particular the challenge posed by the endogeneity of the migration decision. This problem is evident in almost all of the papers that have looked at the impact of migration on child health. Brockerhoff (1990) investigates the effects of female migration on the survival probability of children in Senegal and shows that rural-to-urban migration by mothers improves the survival odds of their children. Ssengonzi, De Jong and Stokes (2002) replicate the analysis for the case of Uganda, once again looking at the effect of female migration on infant mortality. They find that both rural and urban migration significantly increase child survival chances. A related paper by Kanaiaupuri and Donato (1999) examines the effect of migrant remittances on infant survival outcomes in Mexico. In contrast to the two other studies, they find higher rates of infant mortality in communities experiencing intense migration. However, mortality risks are indeed lower in villages with higher migrant remittances. None of these studies deals with the potential selectivity of migration, making it difficult to disentangle the extent to which their results reflect the unobserved characteristics of migrants, their households or their communities as opposed to the migration decision itself. The only exception is recent work by Hildebrandt and McKenzie (2005) who do control for selection into migration and look at several health related outcomes for households in Mexico that have international migrants. They find that migrant households have lower rates of infant mortality and higher birth weights compared to non-migrants. They also find that migration raises the health knowledge of mothers. On the other hand, preventative health care (such as breast-feeding and vaccinations) seem to be less likely for children from migrant households. A possible concern with their work is that they use historical migration networks at the state level 
to instrument for current migration to the US in the communities they study. However, as we discuss below, health outcomes are likely to be significantly affected by village and community level unobservables and the direction of the bias is unclear. ${ }^{7}$

A related literature has looked at gender differences in risk related health outcomes in the South Asian context. These papers have also focused largely on excess female mortality. Rosenzweig and Schultz (1982) argue that gender differences in child survival are due, at least in part, to intra-household resource allocation decisions. Rose (1999) has shown that favorable rainfall shocks increase the likelihood that a girl survives until school age. There is also some evidence in the literature that gender differences in child nutritional status can be important, particularly in times of adverse income and price fluctuations. Muhuri and Preston (1991) summarize some of this literature and argue that the differential allocation of food and health care by gender appear to be important mechanisms through which excess female mortality arises. Behrman (1988) finds that the nutrition of girls suffers more than the nutrition of boys in the lean agricultural season and Behrman and Deolalikar (1990) report that price changes affect the consumption of girls more than the consumption of boys. Focusing on adult nutrition, Dercon and Krishnan (2000) have shown that women tend to bear the burden of idiosyncratic adverse shocks to a disproportionate degree.

The main child growth measures we use in the paper are weight for age (WAZ) and height for age (HAZ) z-scores. Child height, in particular, is a good indicator of underlying health status and studies have shown that children experiencing slow height growth are found to perform less well in school, score poorly on tests of cognitive function, and have poorer psychomotor skills and fine motor skills. They also tend to have lower activity levels, interact less frequently in their environments and fail to acquire skills at normal rates. Studies have also shown that taller women experience fewer complications during child birth, have children with higher birth weights and face lower risks of child and maternal mortality (World Bank 1993). Thus growth faltering in young girls may have inter-generational consequences. Our use of child growth measures thus also makes it possible to check the extent to which possible early childhood nutritional shocks have permanent effects. ${ }^{8}$

\footnotetext{
${ }^{7}$ Alderman and Garcia (1994) and Thomas, Strauss and Henriques (1991) among others have shown that the estimated impact of income and education on child health status will be biased if community level unobservables are ignored. More significantly, Strauss et. al find that it is the quality of health care services that matters the most, as opposed to the more commonly measured health service availability or distance to a health care facility.

${ }^{8}$ The main disadvantages of using anthropometic measures is that body size is likely to be affected by
} 
Studies that use child growth measures to look at health related impacts for children include, in particular, Hoddinott and Kinsey (2001) and Foster (1995). Hoddinott and Kinsey (2001) show that very young children in Zimbabwe grew significantly slower during a period of drought than children in times of normal rainfall. Foster(1995) showed similar results for children after a period of severe floods in Bangladesh. Neither of these studies finds any gender differentials in child growth, however.

The main econometric challenge for this paper lies in dealing with the endogeneity of the migration decision in a context where community level unobservables are likely to be important determinants of the main outcome of interest: child health. We use two strategies to address this potential endogeneity problem. The first is to use instrumental variables to address selection in the migration decision. We use the prevalence rates of migration in the population at the village level as our main instrument for migration and use census level information on landownership in the village to get within village variation in this instrument. We also use a feature of migration that is particular to the context we study to obtain household level variation in our instrument. Mobility and seclusion restrictions on women typically require the presence of an adult male in the household. Households with a single adult male are therefore much less likely to undertake migration. We also show that, conditional on appropriate demographic characteristics, the number of adult males exercises no influence on any outcome of interest. We can therefore interact the village-land group migration network with the number of adult males in a household (males above age 20) to obtain an instrument which varies at the household level. The identification argument is that, conditional on household demographic characteristics and village fixed effects, the incidence of migration at the census level, within specific land ownership groups in a village, interacted with the number of adult males in the household should affect the household's opportunity to send a migrant but is unlikely to be correlated with any unobservable household or child attributes that affect nutritional status.

A second strategy is to confine attention to migrant households and to examine anthropometric outcomes for children born before and after first migration within such households. The advantage of this approach is that it allows us to control for any time invariant unobserved household attributes that may affect both the migration decision and child nutrition.

After accounting for selection into migration, the results indicate that migration has a substantially larger positive impact on growth outcomes for young girls. Moreover, the

inputs other than consumption and is a stock variable. Neither of these is a concern for us since we are not looking at changes in body size for the same child over time. 
growth advantage is sustained among older girls, suggesting potential inter-generational benefits of averting nutritional and other health shocks for girls in early childhood. These results are further validated by restricting the sample to migrant households and comparing the growth outcomes of siblings before and after migration.

The next section of the paper provides the context for our study. Section 3 presents the estimation and identification strategy and presents some preliminary evidence on gender differences in the impact of migration on child nutritional status. We test our main proposition in section 4 . In 4.1 we use our instrumentation strategy to examine gender differences in the impact of migration in the full sample of households. In section 4.2, we restrict attention to migrant households and examine differences in the nutritional status of children, by gender, born before and after migration within the same household. Conclusions and implications follow in section 5 .

\section{Data and Context}

\subsection{Migration}

More than one in four households in rural Pakistan have at least one migrant member. Migrants are typically adult males, who move temporarily to an international or domestic urban destination in search of employment leaving their families in the village. ${ }^{9}$ Most maintain very close ties with their origin households and communities, returning frequently and sending substantial remittances. ${ }^{10}$ This makes the context particularly useful for examining the impact of migration on outcomes in the sending community.

The study uses data from the Pakistan Rural Household Survey (PRHS) 2001-02, which collected detailed information on migration for each household member. ${ }^{11}$ Complete data are available for 2531 rural households in 143 villages in 16 districts across all 4 provinces. The survey contains detailed household and individual characteristics, including demographics, occupation, health, education, investments, assets, household expenditure, and the migration experience of all household members. For migrants, data were also collected on the year and duration of migration, migration destination, remittances, and

\footnotetext{
${ }^{9}$ Close to $80 \%$ of migrants in our study report having undertaken migration in search of employment.

${ }^{10}$ See Addleton (1984), Kazi (1989) and Arif (2004) for a review of migration patterns in Pakistan.

${ }^{11}$ In the PRHS, all individuals who were away from the household at the time of the survey, were classified as households members, provided they were regarded as members of the household before they left and had not set up a permanant home elsewhere. This enabled collection of all relevant data on current migrants.
} 
social networks accessed prior to and post migration. Migrants were interviewed directly when possible. Otherwise, the individual designated as the male head of the household reported migration and other information for each migrant.

For purposes of the analysis we confine attention to male migrants age 18 or older who migrated for economic reasons. ${ }^{12}$ Using this definition, 977 men (about $15 \%$ of all men in this age range) are classified as migrants Of these, $32 \%$ were back from a migration episode in the survey year, the rest were current migrants. Since migration is typically recurrent, a household is classified as a migrant household if it reported at least one male member with some migration experience current or past. At the household level, 699 households ( $26 \%$ of all households) had at least one male migrant.

The median age at first migration in the sample is 22 . The typical migrant is either a household head $(38 \%)$ or an older son of the head (54\%). One indicator of the extent to which migrants are attached to their families of origin in the villages is that over two-thirds are married and have their spouses and/or children living in the village. Almost two-thirds of migrants also reported sending some remittances to their families in the village and three-fourths of those who sent remittances did so on a regular basis. ${ }^{13}$ The survey has a companion section on cash and kind transfers received and given by the household, and the identity of all who send or receive such transfers. The median reported amount remitted annually by migrant household members is about Rs. $24,000 .{ }^{14}$ In contrast, transfers by non-household members are insignificant. ${ }^{15}$

\subsection{Child Growth Measures}

The main child growth measures we use in the paper are weight for age (WAZ) and height for age(HAZ) $z$-scores. ${ }^{16}$ We focus on children between 6 months and 10 years

\footnotetext{
${ }^{12}$ There is virutally no migration among children under 18 . The few who do not live at home move to join a family member or to attend school in a neighboring rural area. Women also typically migrate to join family members, most often a spouse. While $8 \%$ of reported migrants are women, over $82 \%$ report migrating to join a family member. Only 13 women (1\% of the sample of migrants) report migrating for any economic reason.

${ }^{13}$ Remittances from international migrants constitute the single largest source of foreign exchange earnings for the country. According to one estimate, US $\$ 2.4$ billion (or $4 \%$ of the country's GNP) is currently remitted annually by international migrants (see Gazdar (2003))..

${ }^{14}$ About $\$ 500$ annually at the prevailing exchange rate in 2001 .

${ }^{15}$ See Mansuri (2006) for a more extensive discussion of migration destination and remittance flows in rural Pakistan.

${ }^{16}$ The $z$-score is calculated by standardizing a child's height or weight, given age and sex against an international standard of well nourished children. A $z$-score of -1 , for example, indicates that given age
} 
of age. ${ }^{17}$ Weight for age measures underweight and is the most commonly used measure of child nutritional status. It is routinely collected in growth promotion programs and is a particularly good indicator for children under two because of the need to do precise measurements of weight for this age group. Height for age is a measure of possible stunting or chronic malnourishment. It is generally assumed to indicate the long-term, cumulative effects of inadequate nutrition and poor health status. It is thus the measure which has the greatest relevance from our perspective, since we use cross section data and are interested in observing the impact of a nutritional shock at any time in the child's first 3 years of life. For height for age, therefore, we divide children into two groups: 6 months to 3 years and 3-10 years of age. A child is considered malnutrient if either of these indexes falls below two standard deviations $(<-2 \mathrm{SD})$ of the median value of the National Center for Health Statistics/World Health Organization (NCHS/WHO) international reference. Severe malnutrition is identified by index values below $3 \mathrm{SD}$ of the median value. ${ }^{18}$

The final sample of children is confined to those with $z$-scores in the range -6 to 6. ${ }^{19}$ This gives us a total sample of 4731 children for whom we have HAZ scores in the acceptable range (of which 1157 are under age 3) and 4906 children with WAZ scores in this range. About $27 \%$ of these children belong to migrant households. The mean HAZ is -1.92. More than half the sample (54\%) has HAZ scores which are below $-2 \mathrm{SD}$ a level that signifies some stunting and about a third have score below -3 indicating severe stunting. ${ }^{20}$ The mean WAZ in this sample is -1.82 . Close to $44 \%$ of the sample has WAZ scores below -2 SD and $23 \%$ have scores below -3 indicating severe malnourishment. In contrast, $29 \%$ have HAZ scores in the normal range and $31 \%$ have WAZ scores in the normal range.

and sex the child's height is one standard deviation below the median child in that age/sex group. Child height and weight in the PRHS 2001-02 were measured in centimetres and kilograms, respectively.

The reference tables for WAZ and HAZ are taken from the CDC Growth Charts for US (Kuczmarski et al., 2000).

${ }^{17}$ The use of $z$-scores is not recommended for children older than age 10 .

${ }^{18} \mathrm{We}$ do not focus on weight for height (a measure of wasting). Like weight for age, it is sensitive to changes in calorie intake or the effects of disease, but is the best index to use to reflect wasting malnutrition, when it is difficult to determine the exact ages of the children being measured. In the population we study, we measure age well. Acute malnutrition is not as pervasive as malnutrition or stunting. The 1990 DHS estimates that $8.7 \%$ of children nationally are wasted.

${ }^{19}$ Scores outside this range are typically indicative of measurement error in either height, weight or age. In doing this we follow the convention used for dealing with extreme $z$-score values. See for example, Hoddinott and Kinsey (2001).

$\mathrm{X}$ children with $z$-scores outside this range were dropped from the sample. These children do not appear to be a selective group by location, age or gender.

${ }^{20}$ This is somewhat higher than the $48.9 \%$ stunting rate reported for the country as a whole in the Demographic and Health Survey (1990) This is not surprising given that the PRHS sample includes only rural children. 


\section{Empirical Strategy}

\subsection{Econometric Specification and Identification}

In order to assess gender differentials in the impact of migration on child nutritional status, we need to estimate a regression function of the form

$$
Z_{i j v}=\beta_{1} M_{i j v}+\beta_{2} G_{i j v}+\beta_{3} G_{i j v} M_{i j v}+\gamma_{1} C_{i j v}+\gamma_{2} X_{j v}+\eta_{j v}+\varepsilon_{i j v}
$$

Where $Z_{i j v}$ is child's $i$ 's weight (or height) for age $z$-score in household $j$ and village $v$. $M_{j v}$ is an indicator of whether the household has a migrant, $G_{i j v}$ is the child's gender, and $C_{i j v}$ and $X_{j v}$ are vectors of exogenous child and household characteristics. The mean zero error term $\eta_{j v}$ captures the effects of unobserved factors common to a given village and household. Village level unobservables could range from locational advantages, availability or quality of health care and public health interventions to weather related shocks and access to credit or other markets. Household level unobservables could include, in particular, access to credit and insurance markets, and preferences that may influence both the decision to migrate and child nutritional status, including gender differences in the latter. Included in this term would also be the effect of costs that affect child health status but are not observed in the data. The child-specific error term $\varepsilon_{i j v}$ reflects measurement error in WAZ (HAZ) and, potentially, unobserved attributes of the child, including innate health, for example.

Since $M_{j v}$ is likely to depend on at least one of the factors captured by $\eta_{j v}$, we need to contend with a potential endogeneity problem. We tackle the problem in two ways. Our first strategy is to instrument for migration. To do this, we need instruments correlated with the migration decision but uncorrelated with unobserved attributes of the child, the household or the community.

The census based measure of migrant networks within each village $(V M)$ provides us with just such an instrument. ${ }^{21}$ It influences the opportunity to migrate, ${ }^{22}$ but household

\footnotetext{
${ }^{21} \mathrm{~A}$ number of recent papers have used a measure of the migrant network to instrument for migration. Migrant networks are seen as reducing the costs of migration for potential migrants via two channels First, they constitute an information network which can educate potential migrants about conditions in specific migration destinations as well as potential hazards and costs, both at home and in migration destinations (Massey 1988; Orrenious (1999)). Second, they serve to relax credit constraints (Genicot and Senesky (2004)). A number of studies have also shown that networks increase the economic returns to migration (Munshi (2003); McKenzie (2005)).

${ }^{22}$ This is indeed borne out in several empirical studies. For example, Winters et. al. (2001) show that the
} 
specific unobservables in $\eta_{j v}$ or child specific unobservables in $\varepsilon_{i j v}$ are unlikely to be correlated with the migration network at the village level.

The PRHS 2001-02 includes a complete census of all village households which ascertained the household's current migration status. ${ }^{23}$ Using this, we construct a measure of the migration network for each village in our sample as the proportion of households in the village with a current migrant. While this census based measure of migrant networks is unlikely to be correlated with household specific unobservables in $\eta_{j v}$, this is of course not the case for any number of village level unobservables which could well be correlated with both the propensity to migrate at the village level and village average child outcomes. ${ }^{24}$ In order to deal with this problem, we need an instrument which varies within the village.

To get such an instrument we combine information on the migrant status of households with census information on their landholdings, to create a measure of the migrant network for different landholding groups in each village. ${ }^{25}$ Since land is primarily inherited in rural Pakistan, concerns about changes in land distribution due to migration are unwarranted. ${ }^{26}$ Inequalities in land ownership are also pervasive, ${ }^{27}$ and access to land is an important marker of social and political status and is typically reflected in village settlement patterns. Given this, we expect that access to migrant networks may well vary significantly across landholding groups within a village. This gives us within village variation in the migrant

probability of migration to the United States is higher for households living in Mexican communities which have greater experience with migration. Banerjee (1991) and Caces(1986) have shown the importance of networks in the rural-urban migration decision in the Indian and Philippine context respectively. Ilahi and Jafarey (1999), have shown the importance of extended family networks in financing migration costs in Pakistan.

${ }^{23}$ In the census, $14 \%$ of households report a current migrant. This is significantly below the migration incidence we get from the household survey since the latter is not restricted to current migrants. It is worth noting that the number of households in the sample with a current migrant is just above $13 \%$, as we would expect from the census.

${ }^{24}$ It is important to note here that anthropometric growth measures reflect an amalgam of household and community inputs, including not just food intake and the ability to ward off infections, but also health care availability and quality, sanitation and public health campaigns. As such, there is often a weak correlation between household variables such as income, assets and education and levels of malnutrition. Alderman and Garcia (1994) point to this in the case of Pakistan, where levels of child malnutrition do not appear to be in line with reductions in poverty. They argue that community level variables and public health interventions may play a larger role in lowering malnutrition. It is therefore important in our context to examine wealth impact after controlling for community level unobservables.

${ }^{25}$ Households with no land; households who own up to 15 acres of land; households who own between 16 and 50 acres; and those who own more than 50 acres.

${ }^{26}$ In the PRHS 2001-02, for example, over $85 \%$ of land owned by sample households is reported as having been acquired via inheritance or as a gift from parents during their lifetime. We are thus not worried that more entrepreneurial households may acquire land, undertake higer levels of migration and invest more in their children..

${ }^{27}$ The mean land gini at the village level is .75 
network, conditional on the household's own inherited land, allowing us to difference out any village fixed effects.

Differencing equation 1 across households within a village, yields

$$
Z_{i j}=\beta_{1} M_{j}+\beta_{2} G_{i}+\beta_{3} G_{i} M_{j}+\gamma_{1} C_{i j}+\gamma_{2} X_{j}+\zeta_{i j}
$$

where $\zeta_{i j}=\eta_{j}+\varepsilon_{i j}$.

We use a feature of migration that is particular to the context we study to get further within village variation in our instrument set. Mobility restrictions on women typically require the presence of an adult male in the household. Indeed, households without an adult male are a rare feature in rural Pakistan (less than 1\%). Households with a single adult male are therefore unlikely to undertake migration. One might argue, however, that the number of adult males in the household could affect child health through any number of channels. We show however, that conditional on appropriate household demographic characteristics and a measure of inherited land wealth, which is clearly independent of the migration decision, the number of adult males in the household has no residual impact on any outcomes of interest.

The set of exogenous child characteristics, $C_{i j v}$, include the child's gender, age and age squared, mother's and father's level of education (in completed grades), mother and father's age, mother's height, the total number of siblings, the presence of an older brother or sister under age 18 and the presence of a grandmother and grandfather in the house. The rationale for this last set of variables is that young children who have grandparents in the house may get better supervision and child care and possibly also some additional nutritional resources. The set of exogenous household level characteristics, $X_{j v}$, includes a further set of demographic controls, specifically, an indicator for whether there is more than one married male with coresident spouse and/or children in the household and the household dependency ratio. It also includes the household's inherited land holdings (in acres) our main control for household wealth. Given this set of child and household characteristics, we show that the exclusion restriction on the number of adult makes is valid. Thus $E\left[V M \zeta_{i j}\right]=E\left[N A \zeta_{i j}\right]=0$ should hold to a reasonable approximation and provides identification.

A second strategy for dealing with the potential endogeneity of the migration decision is to restrict attention to migrant households and use information on the year of migration to compare siblings before and after migration. Since weight for age is likely to be sensitive to short term fluctuations in weight, we do this exercise only for the height for age $z$-score. 
Specifically, children are classified into two groups: those born before and those born after the first migration episode for the household. Differences in the nutritional status of children born before and after migration within the same household, should then be free of any bias due to time invariant household level unobservables. Specifically, we replace the indicator $M_{j}$ with a child specific variable $B B_{i j}$ which takes the value 1 if the child was born before the first migrant left the household. Let us suppose, for the sake of exposition, that we have a sample consisting of two children, one born before migration $\left(B B_{i j}=1\right)$ and the other after migration $\left(B B_{k j}=0\right)$. In this case the first difference estimator is identical to the household fixed effect estimator (which we use in the empirical work). Replacing $M_{j}$ in 1 with $B B_{i j}$ and differencing the equation across children within a household, yields

$$
\Delta Z_{j}=\beta_{1} \Delta B B_{j}+\beta_{2} \Delta G_{j}+\beta_{3} \Delta G_{j} M_{j}+\gamma_{1} \Delta C_{j}+\Delta \varepsilon_{j}
$$

where $\Delta$ is the difference operator and $\Delta B B_{j}=B B_{i j}$. The OLS estimates of $\beta_{1}, \beta_{2}$ and $\beta_{3}$ from this regression will be consistent under the reasonable assumption that $E\left[B B_{i j} \Delta \varepsilon_{j}\right]=0 .^{28}$

\subsection{Preliminary Evidence: Gender Differences in Child Growth and Migration}

In tables 2 and 3 we present some preliminary statistics on HAZ and WAZ in migrant and non migrant households. Table 2 presents mean HAZ and WAZ for young children and table 3 for older children. Children in migrant households have consistently higher mean $z$-scores than children in non-migrant households and these differences are significant at the $1 \%$ level for both boys and girls, moreover among young children, the HAZ differential is only significant for girls. Figures 1-6 present kernel density estimates of the distributions of WAZ and HAZ for migrant and non-migrant households. Figures 1 and 2, respectively, show the WAZ and HAZ scores by gender for the full sample (children 6 months to 10 years). The estimated kernel densities show that children from migrant households have higher WAZ and HAZ z-scores (the Kolmogorov-Smirnov (KS) test for the equality of distributions by migration status rejects the equality of the two distributions for both girls and boys with $p$-value <.000). The following four figures show similar kernel densities for

\footnotetext{
${ }^{28}$ Note that since $\eta_{j v}$ differences out of this equation, we do not need to be concerned about the possibility that migrant households constitute a selective sample (i.e, that $E\left[\eta_{j v} \mid\right.$ Migrant $] \neq 0$ ).
} 
the younger and older age groups. For HAZ, this makes no difference. (KS has $p$-value $<.000$ in all cases). For WAZ, results are a little weaker for the older age group but still significant (the KS test for this group has a $p$-value $<.04$ for both boys and girls).

Table 4 provides another perspective on differences in child growth measures between migrant and non-migrant households. Children are classified by the severity of malnutrition into four groups, from severely malnourished $(<-3 \mathrm{SD})$ to normal $(>-1)$. Focusing first on the very young (columns 2-4), we find that children in migrant households are significantly less likely to be severely underweight and significantly more likely to be in the normal or mildly underweight group $(p$-value $<.01)$. They are also significantly less likely to be severely stunted $(p$-value $<.05)$ and this effect is more pronounced for girls. These effects are sustained in the older age group, with significantly fewer children from migrant households being severely malnourished (HAZ $p$-values $<.01$ and WAZ $p$-values $<.05$ ) and significantly more children being in the mild to normal group. We do not observe any gender differences in these outcomes for this age group.

These descriptive statistics, though based on simple mean comparisons, suggest that children in migrant households do better than their counterparts in non-migrant households overall and set the stage for our main question: do girls in migrants households do relatively better than their counterparts in non-migrant households as compared to boys. We turn to this issue next.

\section{Main Results}

Tables 5-6 present the estimation results for HAZ and WAZ respectively. The first specification in all cases (column 1) presents the OLS estimates of the migration coefficient and its interaction with child gender under the assumption that the migration decision is uncorrelated with unobserved village and household attributes.

In specification 2 we relax the assumption that the migration decision is uncorrelated with unobserved household characteristics which could influence child growth. Since the endogeneity bias in the migration coefficient could work in either direction, we have no priors on the direction of the bias. The instrument in this specification is the village migration network and its interaction with child gender. The explanatory power of the instruments, conditional on the included household and child characteristics, is extremely

high in all cases. The coefficient estimates for the full set of controls for this specification are presented in Appendix Table A1. 
In specification 3, we add the number of adult males to the set of controls. It fails to attract a significant coefficient and the strength of the instruments is unaffected. This confirms that the number of adult males exercises no residual influence on child health, conditional on inherited household wealth and the set of demographic controls included in the second stage.

Specification 4 adds tehsil fixed effects. ${ }^{29}$ Specification 5 adds village fixed effects. The joint explanatory power of our instruments, conditional on the village fixed effect and included household and child characteristics, is high in all cases. The instruments also easily pass the overidentification test. All statistics are reported at the end of each table. The first stage is reported in appendix table A1 for the HAZ sample.

Given the epidemiological evidence on the impact of stature by age 3 on adult height, we next check whether any gains in height are obtained by age 3 and whether these are significantly differentiated by gender. Column 5 of table 5 reports this. Next we check if any height gains are sustained as children age. We do this by looking at the HAZ scores of older children in our sample. Column 6 of table 5 reports this. Splitting the sample by age reduces sample size significantly, however, making the less restrictive village fixed effects specification inefficient. However, we can still control for tehsil fixed effects. Only the controls which are significant in the full sample tehsil fixed effects specification are included in specification 5 and 6 .

The control variables are jointly significant and several interesting features stand out. First, all mother variables, height, age and education have very significant positive effects on child height and weight $z$-scores. However, none of the father variables have nay effect. Second, the presence of older children tends to reduce both height and weight $z$-scores but the effects are much larger and more significant if there is an older girl in the house. Contrary to expectations, however, the presence of an older girl does not have a differentially larger effect on younger girls. Third, the presence of grandparents has two opposing and highly significant effects. The presence of a grandmother has a positive effect on both $z$-scores, while the presence of a grandfather has a large negative effect. Finally, inherited land wealth has no effect on either $z$-score.

Table 7 presents the estimation results from a comparison of siblings. The variable of interest $B B$ takes the value 1 if the child is born in the year of migration or earlier. ${ }^{30}$ Since our interest is in assessing whether children within the same household do better

\footnotetext{
${ }^{29}$ The tehsil is an administrative unit below the district level.

${ }^{30}$ Since we do not know the month of migration, child age needs to be rounded to the nearest year. Therefore children born in the year of first migration are treated as being born before first migration.
} 
post-migration, we include all children age 2 to 10 years of age and restrict the sample to households whose first migration episode was in 1992 or later. All specifications include a household fixed effect and controls for the child's age and age squared. About a fourth of the sample of children are born after migration.

\subsection{The Impact of Migration on Child Growth: IV Estimates}

Migration has a large positive effect on both measures of child growth and there are very substantial differences by gender. Instrumenting increases the coefficient estimates, indicating a negative selection bias. Removing the potential effects of community unobservbles through tehsil and village fixed effects in columns 4 and 5 respectively also substantially increases the estimated coefficient on migration.

Focusing first on child height, we find that young girls in migrant households are indeed taller than girls in non-migrant households and the difference is significant at the $5 \%$ level. While girls in non-migrant households are about , 25 SD below boys, migration increases the HAZ score of girls by $1.5 \mathrm{SD}$ in comparison to $.82 \mathrm{SD}$ for boys, using specification 4. As a consequence, girls in migrant households actually do better than boys in such households in absolute terms. Once we split the sample by age, the HAZ score for younger girls increases by almost $1.8 \mathrm{SD}$, while the increase in only .36 SD for boys, with the consequence that the HAZ score for girls and boys in this age group is a full SD apart and this difference is significant at the $5 \%$ level.

This effect is almost fully sustained among older girls. The coefficient on gender differentiated effects is now significant at the $1 \%$ level. Older girls gain about $1.6 \mathrm{SD}$ in HAZ score while boys gain only .7 SD.

This large impact on girls and the relatively weak effect on boys suggests that girls in rural Pakistan do indeed bear a higher degree of uninsured household risk. Further, given the epidemiological evidence on the impact of height by age 3 on adult height, the fact that the impact of migration on the height of young girls is carried over as girls grow, provides support to the contention that the ability to avert growth shocks at a young age can have persistent positive growth effects.

Turing next to the evidence on WAZ scores, the village fixed effects specification (4) suggests that girls from migrant households have better weight for age $z$-scores than do boys. While boys are better off by about .21 SD in non migrant households, girls in migrant households more than make up this loss, gaining 1.21 SD against a gain of about .6 SD for boys. Since weight for age is a short term measure, subject to substantial 
fluctuation near the time of measurement, there is no advantage in splitting the sample by age group.

While these results are extremely strong, our second strategy provides us with another and more direct test of our main hypothesis.

\subsection{The Impact of Migration on Child Growth: Household Fixed Effects Estimates}

Columns 1 and 2 present the results by child gender. While the effect of being born before migration is negative and significant at the $5 \%$ level for girls, there is no discernible effect on boys. Column 3 reports results for the pooled sample. Now $\beta_{3}$, the coefficient on the the interaction term, is negative and highly significant ( $\mathrm{p}$-value $<.05$ ), while $\beta_{1}$, is actually positive, though not at all significant. In sum, girls who are born before first migration in the same household do much worse on height for age than girls who are born after first migration-while there is absolutely no effect of the timing of migration on the heights of boys.

\section{Conclusions}

Migration is one mechanism through which poor rural households in many developing countries attempt to cope with income risk. In this paper we ask whether temporary economic migration by a household member allows rural households to avoid costly risk coping strategies. We focus on early child growth since there is considerable epidemiological evidence that very young children are particularly vulnerable to shocks that lead to growth faltering, with substantial long-term health consequences.

The data come from rural Pakistan, where, as in the rest of Asia, son preference is substantial and there are large gender gaps in most developmental outcomes. As such, our interest is in examining also whether migration induced resource flows allow households to extend better nutrition and health care protection to girls. Recent work on the intrahousehold allocation of resources and risk has also shown that gender differences in the relative burden of risk may be important and that the allocation of resources to daughters is often one margin along which poor households adjust to uninsurable transitory income shocks.

The main child growth measures we use are weight for age (WAZ) and height for age (HAZ) $z$-scores. For our purposes, the child's height for age, a measure of stunting, is 
of greater interest since it reflects the cumulative effects of nutritional and other health related shocks during the child's early years. Epidemiological evidence also suggests that nutritional and health shocks at a very young age are likely to generate long term growth faltering with substantial and irreversible adverse consequences for children in a large range of developmental outcomes.

The main econometric challenge for the paper is the endogeneity of the migration decision. We resolve this in two ways. We instrument for selection into migration using data on village migrant networks and household demographic characteristics which are correlated with the migration decision but not the outcomes of interest. This gives us a measure of migration networks which varies within the village, allowing us to both instrument for selection in the migration decision and to control for unobserved village characteristics that could impact child growth. Next, we restrict the sample to migrant households and exploit information on the timing of first migration to split children in each household into two groups, those born before the household's first migration episode and those born after. We then use this information to estimate the impact of the child's migration related birth status on the child's height for age. This allows us to compare outcomes for siblings differentiated by their attained age by the date of migration.

We find that migration, appropriately instrumented, has a positive and extremely significant impact on height for age for girls. In contrast, the effects are much smaller for boys, suggesting that boys may get preference in terms of nutrition and health care when resources are stretched. Moreover, when we split the sample by age group we find that the height advantage of young girls is sustained in the older age group. This result underscores the long term salutary benefits of averting nutritional and other health shocks in early childhood. Estimation using child weight for age $z$-scores yield similar results. Our results also suggest that, as expected, selection into migration as well as community level unobservables are quite important.

A comparison of siblings further corroborates our results on child height. Girls born before the household's first migration episode do much worse than girls born after. Now, however, there is no discernible difference among boys born before and after the first migration episode. One of the main disadvantages of using growth measures like height for age to examine changes in growth for a given child is that height for age is a stock variable which gives a cumulative picture of the child's overall growth status. Short term shocks, are thus unlikely to show up immediately in height and the child's ability to withstand such shocks is also likely to be determined by previous exposure. Our strategy allows us 
to avert this difficulty by examining differences in the growth outcomes of children who face more or less the same set of community and household attributes and preferences but differ in one crucial respect: some of them were born after the household acquired a superior channel for risk management. The fact that this last set of results perfectly echoes our earlier findings, using instrumental variables, is therefore particularly heartening and suggests that our results are robust to selection in the migration decision. 


\section{References}

[1] Alderman H. and M. Garcia, (1994): "Food Security and Health Security: Explaining the Levels of Nutritional Status in Pakistan," Economic Development and Cultural Change, 42(3): 485-507

[2] Banerjee (1991): "The Determinants of Migrating with a Pre-arranged Job and the Initial Duration of Urban Unemployment: An Analysis Based on Indian Data on Rural to Urban Migration," Journal of Development Economics, 36(2) 337-51

[3] Behrman, J.R. and A. Deolalikar, (1988): "Health and Nutrition" Chapter 14 in Handbook of Development Economics, 631-711

[4] Behrman, J.R. (1998): "Intrahousehold Allocation of Nutrients in Rural India: Are Boys Favored? Do Parents Exhibit Inequality Aversion?" Oxford Economic Papers, 40(1): $32-54$

[5] Brockerhoff, M.,(1990): "Rural to Urban Migration and Child Survival in Senegal." Demography, 27(4):601-616

[6] Cases, Fe, (1986): "Immigrant Recruitment into the Labor Force: Social Networks Among Filipinos in Hawaii," Amerasia Journal 13(1) 23-28

[7] Chen L., E. Huq and S. D'Souza, (1981) "Sex bias in the family allocation of Food and Health Care in Rural Bangladesh." Population and Development Review, 7(1):55-70

[8] Das Gupta, M.(1987): "Selective Discrimination Against Female Children in India." Population and Development Review, 13:77-101

[9] Monica Das Gupta and Li Shuzhuo, (1999): "Gender Bias in China, South Korea and India 1920-1990: The Effects of War, Famine and Fertility Decline," Development and Change, 30(3):619-652

[10] Dercon, S. and P. Krishnan, (2000): "In Sickness and in Health: Risk Sharing Within Households in Rural Ethiopia." Journal of Political Economy, 108(4): 688-727

[11] Durrant, V. and Sathar, Z., (2000): Greater Investments in Children Through Women's Empowerment: A Key to Demographic Change in Pakistan. The Population Council, Working Paper No.137 
[12] Fafchamps Udry and Czukas (1998):

[13] Foster, A. (1995): "Prices, Credit Constraints and Child Growth in Rural Bangladesh." Economic Journal, 105(43):551-570

[14] Gazdar, Haris (2003): "A Review of Migration Issues in Pakistan." Mimeo.

[15] Genicot, G. and S. Senesky, (2004): " Determinants of Migration and "Coyote" Use among Undocumented Mexicans in the United States," Mimeo, Georgetown University

[16] Glewwe, P. ,1999, "Why does mother's schooling raise child health in developing countries? Evidence from Morocco," Journal of Human Resources, 34(1):124-59.

[17] Hildebrandt, N. and D. J. McKenzie, (2005): "The Effects of Migration on Child Health in Mexico", forthcoming, Economia

[18] Hoddinott J. and B. Kinsey (2001): "Child Growth in the Time of Drought," Oxford Bulletin of Economics and Statistics, 63(4):409-436

[19] Ilahi, N. and S. Jafarey, (1999): "Guestworker Migration, Remittances and the Extended Family: Evidence from Pakistan," Journal of Development Economics, 58:485512

[20] Jacoby and Skoufias (1997): "Risk, Financial Markets and Human Capital in a Developing Country," Review of Economic Studies, 64:311-336

[21] Kazi, S., (1989): "Domestic Impact of Overseas Migration: Pakistan," in To the Gulf and Back, Rashid Amjad (ed.) International Labour Organization. Development Bank.

[22] Kanaiaupuni, S.M. and K.M. Donato, (1999): "Migradollars and Mortality: The Effects of Migration on Infant Survival in Mexico." Demography, 36(3): 339-353

[23] Kochar (1998): "Smoothing Consumption by Smoothing Income: Hours of Work Responses to Idiosyncratic Shocks Agricultural Shocks in Rural India," Review of Economics and Statistics, 81:50-61

[24] Mansuri, Ghazala, (2006): "Temporary Economic Migration and Rural Development in Pakistan, Mimeo, Development Research Group, The World Bank. 
[25] Martorell R. (1995), "Results of the INCAP follow up study," Journal of Nutrition, 125 (suppl): 1127S-1138S

[26] Martorell R., (1999): "The Nature of Child Malnutrition and its Long Term Implications," Food and Nutrition Bulletin, 20:288-292

[27] Martorell R. Khan K.L. and D. G. Schroeder, (1994): "Reversibility of Stunting: Epidemiological Findings in Children from Developing Countries," European Journal of Clinical Nutrition, 48 (suppl): 45S-57S

[28] Massey, D. J. Arango, G Hugo, A. Kouaouci, A. Pellegrino and J. E. Taylor (1993): "Theories of International Migration: A Review and Appraisal," Population and Development Review, 20(4):699-751

[29] Menjivar, Cecilia (1995): "Kinship Networks Among Immigrants: Lessons from a Qualitative Comparative Approach," International Journal of Comparative Sociology, $36(3-4): 219-32$

[30] Montgomery, James (1991): "Social Networks and Labor Market Outcomes: Towards an Economic Analysis," American Economic Review, LXXXI: 1408-1418

[31] Morduch, J., (1995): "Income Smoothing and Consumption Smoothing," Journal of Economic Perspectives, 9:103-114

[32] Munshi, Kaivan (2003): "Networks in the Modern Economy:Mexican Migrants in the U.S. Labor Market," The Quarterly Journal of Economics, 549-599.

[33] Orrenius, P.M., (1999):" The Role of Family Networks, Coyote Prices and the Rural Economy in Migration from Western Mexico:1965-1994," Federal Reserve Bank of Dallas Working Paper No. 9910

[34] Rose, E., (1999): "Consumption Smoothing and Excess Female Mortality in Rural India," The Review of Economics and Statistics, 81(1):41-49

[35] Rosenzweig, M. and T. P. Schultz, (1982): "Market Opportunities, Genetic Endowments and Intra-family Resource Distribution: Child Survival in Rural India," The American Economic Review, 72(4): 803-815

[36] Sahn, D.E. and Stifel, D.C., (2002): Parental Preferences for Nutrition of Boys and Girls: Evidence from Africa." The Journal of Development Studies, 39(1): 21-45 
[37] Stark, O. and Levhari, (1982): "On Migration and Risk in LDCs," Economic Development and Cultural Change, 31(1) 191-96

[38] Stark, O. and Bloom, David E., (1985): "The New Economics of Labor Migration." The American Economic Review, 75(2): 173-178.

[39] Schultz, T. P., 1989, Benefits of educating women, Background Papers Series, Population and Human Resources Department, Washington DC: World Bank.

[40] SSengonzi et. al., (2002): "The Effect of Female Migration on Infant and Child Survival In Uganda." Population Research and Policy Review, 21: 403-431

[41] Strauss, J. and D. Thomas, 1995, Human resources: Empirical modeling of household and family decisions, In J. Behrman and T.N. Srinivasan (eds) Handbook of Development Economics, Volume 3A, Chapter 34.

[42] Summers, L., (1992), "Investing in all the people," Policy Research Working Papers, Report No. WPS 905, Washington DC: World Bank

[43] Udry, C., (1990): "Credit Markets in Northern Nigeria: Credit as Insurance in a Rural Economy,"

[44] Winters, Paul, Alain de Janvry and Elizabeth Sadoulet, (2001): "Family and Community Networks in Mexico-U.S. Migration," Journal of Human Resources, Vol. 36, No.1: 159-184

[45] Pakistan Country Gender Assessment, (2005). The World Bank.

[46] Zia, S. and F. Bari, 1999, Baseline Report on Women's Participation in Political and Public Life, Aurat Publication and Information Services Foundation, Lahore. 

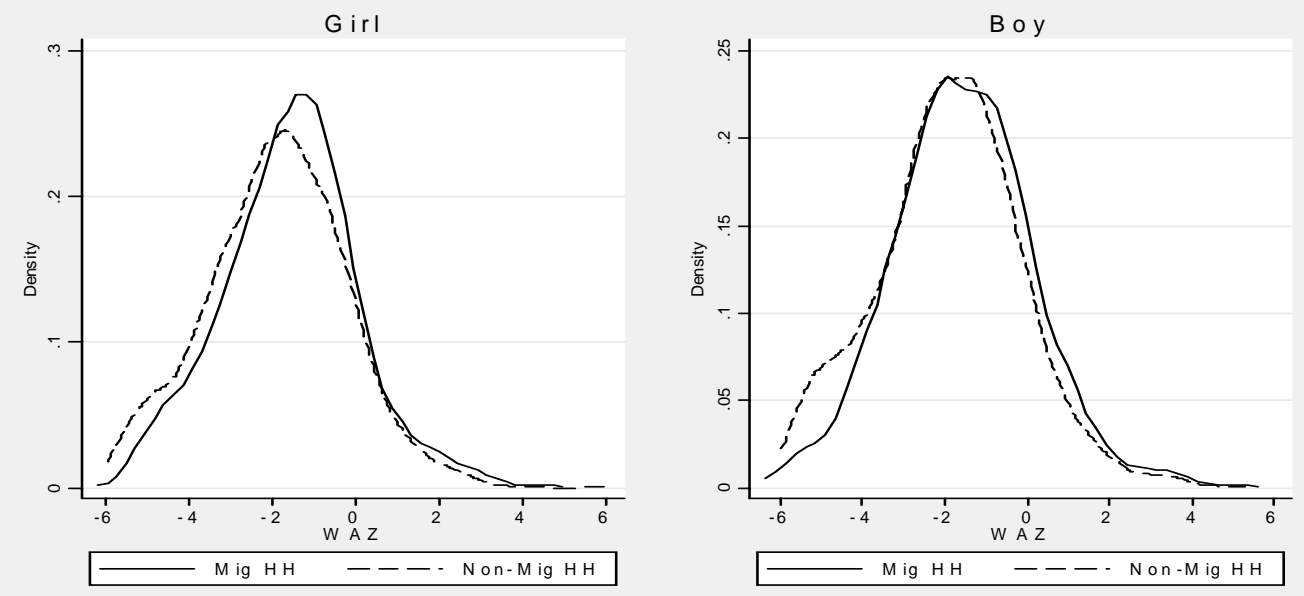

Figure 1: Kernel Density Estimates of WAZ. All children..
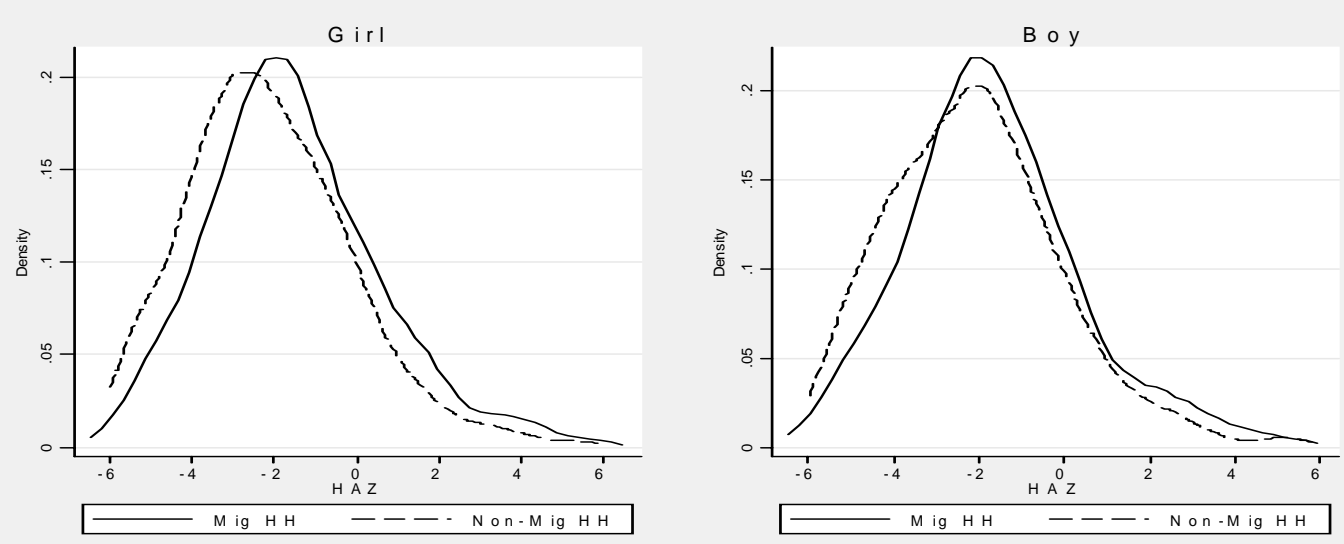

Figure 2: Kernel Density Estimates of HAZ. All Children 

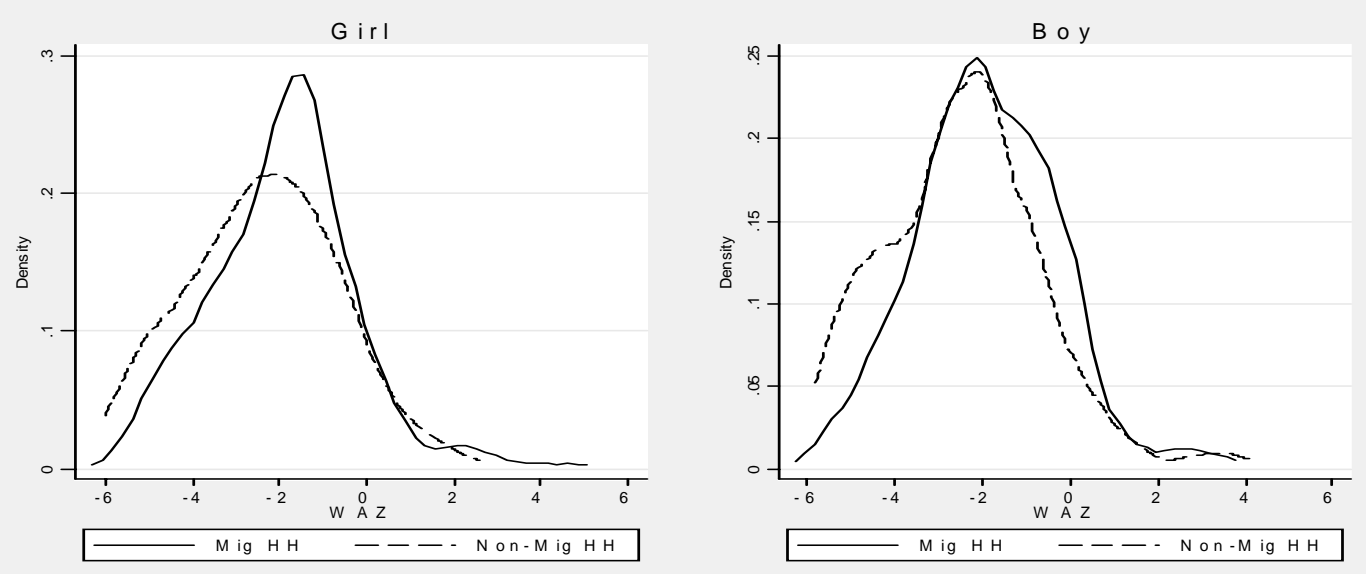

Figure 3: Kernel Density Estimates of WAZ. Children 6 months to 3 years
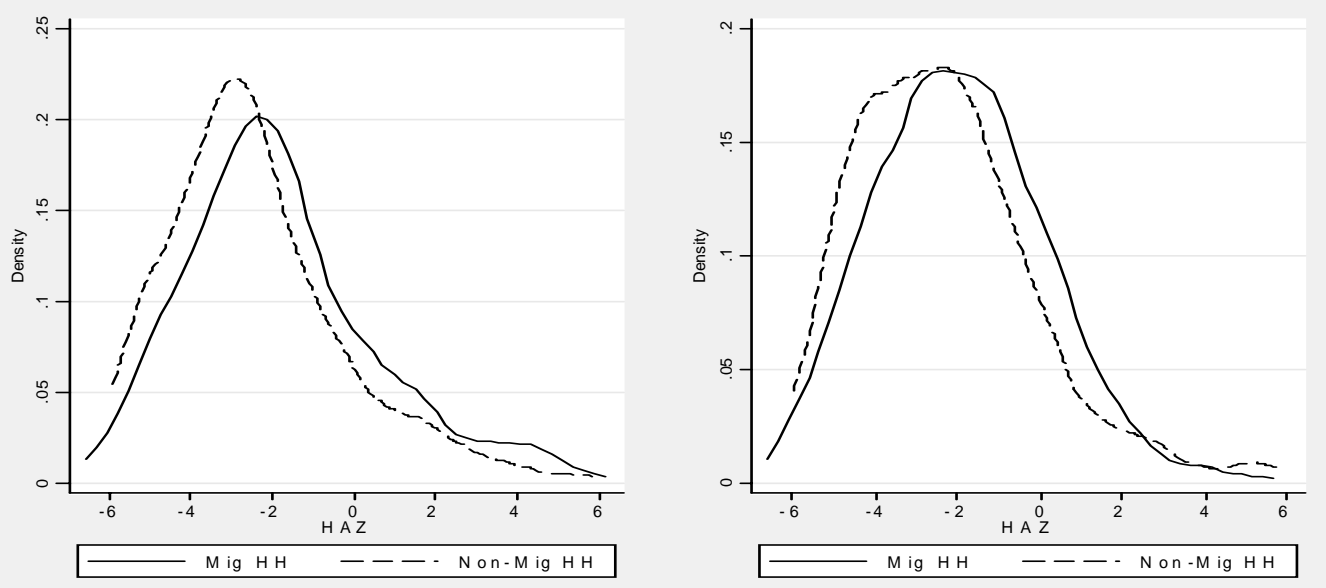

Figure 4: Kernel Density Estimates of HAZ. Children 6 months to 3 years. 

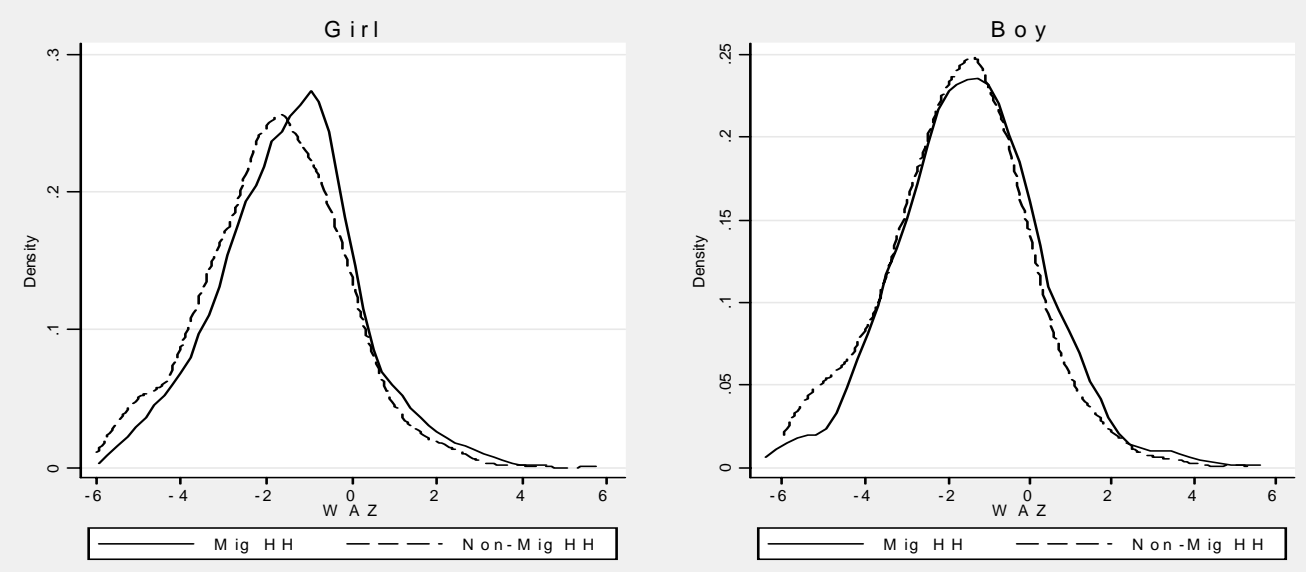

Figure 5: Kernel Density Estimates of WAZ. Children 3-10 years old
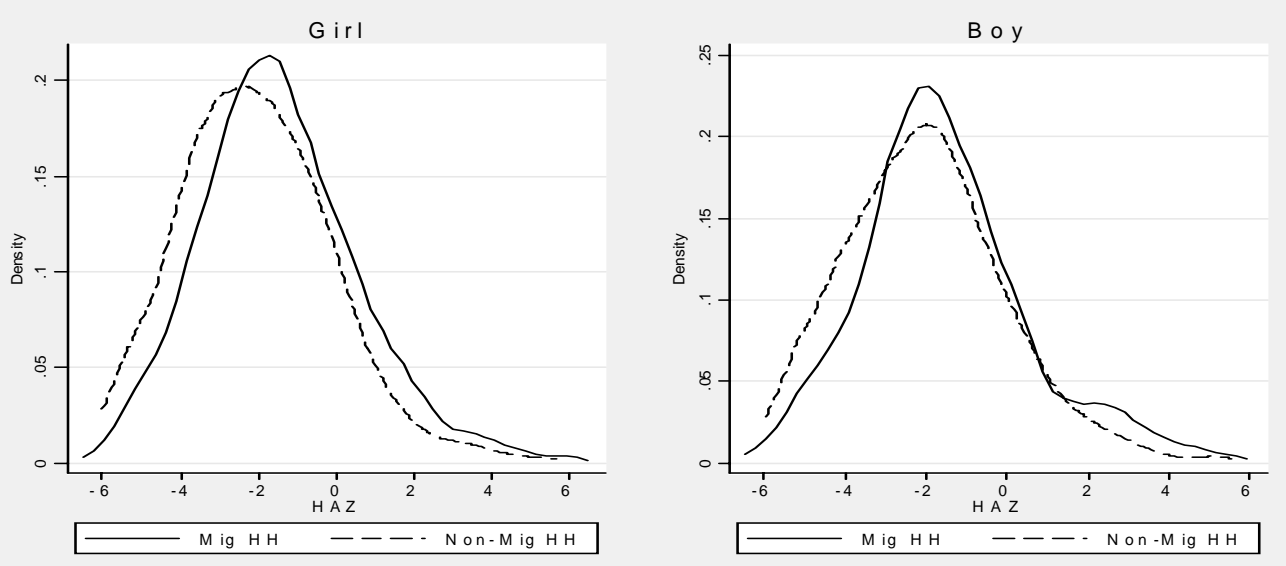

Figure 6: Kernel Density Estimates of HAZ. Children 3-10 years old 
Table 1: Gender Differences in the Effects of Wealth on Child Health Among Non-Migrants

\begin{tabular}{ccccccc}
\hline \hline & \multicolumn{2}{c}{ All } & \multicolumn{2}{c}{ Boys } & \multicolumn{2}{c}{ Girls } \\
Dependent Variable & WAZ & HAZ & WAZ & HAZ & WAZ & HAZ \\
Wealth Index & $.09^{* * *}$ & $.12^{* * *}$ & $.07^{*}$ & $.08^{*}$ & $.12^{* * *}$ & $.18^{* * *}$ \\
& $(.03)$ & $(.03)$ & $(.04)$ & $(.05)$ & $(.04)$ & $(.05)$ \\
\hline \hline Observations & 3234 & 3110 & 1646 & 1564 & 1588 & 1546 \\
\hline \hline Village Fixed Effects & Yes & Yes & Yes & Yes & Yes & Yes \\
$F$ & 17.2 & 14.9 & 11.8 & 6.3 & 8.3 & 9.5 \\
\hline
\end{tabular}

Notes:Standard errors in parentheses $(* * *$ denotes a p-value $<0.01 ; * *$ denotes

a p-value $<0.05 ; *$ denotes a p-value $<0.10$ ). The dependent variable is a child's

HAZ or WAZ score. The sample includes all children 6 months-to 10 years of age in

non-migrant households. The set of controls includes the child's age and age squared, mother's age and height, the number of siblings and the household dependency ratio. 
Table 2: HAZ and WAZ of Children Age 6 months to 3 years in Migrant and Non-Migrant Households

\begin{tabular}{|c|c|c|c|c|c|c|c|}
\hline & \multicolumn{2}{|c|}{$\overline{\text { All }}$} & \multicolumn{2}{|c|}{$\mathrm{MH}$} & \multicolumn{2}{|c|}{$\mathrm{NMH}$} & \\
\hline & Count & " HAZ & Count & " HAZ & Count & 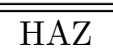 & " Mean Difference in HAZ \\
\hline All & 1157 & -2.188 & 323 & -1.881 & 908 & -2.297 & $-.42^{* * *}$ \\
\hline Boys & 560 & -2.183 & 148 & -1.945 & 445 & -2.329 & $-.38 * *$ \\
\hline \multirow[t]{2}{*}{ Girls } & 597 & -2.193 & 175 & -1.785 & 463 & -2.347 & $-.56^{* * *}$ \\
\hline & \multicolumn{2}{|c|}{ All } & \multicolumn{2}{|c|}{$\overline{\mathrm{MH}}$} & \multicolumn{2}{|c|}{$\mathrm{NMH}$} & \\
\hline All & $\begin{array}{l}\text { Count } \\
1203\end{array}$ & $\begin{array}{l}\text { WAZ } \\
-2.246\end{array}$ & $\begin{array}{c}\text { Count } \\
338\end{array}$ & $\begin{array}{l}\text { WAZ } \\
-1.836\end{array}$ & $\begin{array}{l}\text { Count } \\
950\end{array}$ & $\begin{array}{l}\text { WAZ } \\
-2.392\end{array}$ & $\begin{array}{c}\text { Mean Difference in WAZ } \\
-.56^{* * *}\end{array}$ \\
\hline Boys & 613 & -2.276 & 151 & -1.800 & 504 & -2.41 & $-.62^{* * *}$ \\
\hline Girls & 590 & -2.216 & 187 & -1.865 & 446 & -2.363 & $-.49 * * *$ \\
\hline
\end{tabular}

Notes: NMH refers to non-migrant housholds. MH refers to migrant households $* * *$ denotes a $\mathrm{p}$-value $<0.01 ; * *$ denotes a $\mathrm{p}$-value $<0.05$

Table 3: HAZ and WAZ of Children Age 3 - 10 Years in Migrant and Non-Migrant Households

\begin{tabular}{|c|c|c|c|c|c|c|c|}
\hline & \multicolumn{2}{|c|}{ All } & \multicolumn{2}{|c|}{$\mathrm{MH}$} & \multicolumn{2}{|c|}{$\mathrm{NMH}$} & \\
\hline & Count & HAZ & Count & HAZ & Count & HAZ & Mean Difference in HAZ \\
\hline All & 3574 & -1.922 & 618 & -1.584 & 2051 & -2.024 & $-.44^{* * *}$ \\
\hline Boys & 1798 & -1.951 & 303 & -1.632 & 1063 & -2.042 & $-.41^{* * *}$ \\
\hline \multirow[t]{3}{*}{ Girls } & 1776 & -1.892 & 314 & -1.538 & 988 & -2.005 & $-.47^{* * *}$ \\
\hline & \multicolumn{2}{|c|}{ 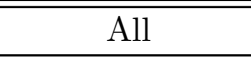 } & \multicolumn{2}{|c|}{$\mathrm{MH}$} & \multicolumn{2}{|c|}{$\mathrm{NMH}$} & \\
\hline & Count & WAZ & Count & WAZ & Count & WAZ & Mean Difference in WAZ \\
\hline All & 3703 & -1.698 & 645 & -1.450 & 2139 & -1.773 & $-.32^{* * *}$ \\
\hline Boys & 1851 & -1.669 & 321 & -1.381 & 1097 & -1.754 & $-.37^{* * *}$ \\
\hline Girls & 1853 & -1.728 & 324 & -1.519 & 1042 & -1.794 & $-.27^{* * *}$ \\
\hline
\end{tabular}

Notes: NMH refers to non-migrant housholds. MH refers to migrant households $* * *$ denotes a p-value $<0.01 ; * *$ denotes a $\mathrm{p}$-value $<0.05$ 
Table 4: Malnutrition Among Children in Migrant and Non-Migrant Households

\begin{tabular}{ccccccc}
\hline \hline $\begin{array}{c}\text { Degree of Malnutrition } \\
\text { by Z-score Interval }\end{array}$ & NMH & MH & Difference & NMH & MH & Difference \\
\hline \hline & \multicolumn{7}{c}{ Boys } \\
\hline \hline Weight for Age (WAZ) & \multicolumn{7}{c}{6 mths-3 years } & \multicolumn{3}{c}{3 -10 years } \\
\cline { 2 - 8 } Severe $(<-3)$ & .35 & .23 & $.12^{* * *}$ & .22 & .17 & $.05^{* *}$ \\
Moderate $(-3$ to -2$)$ & .26 & .25 & .01 & .20 & .18 & .02 \\
Mild $(-2$ to -1$)$ & .19 & .22 & -.03 & .25 & .23 & .02 \\
Normal $(>-1)$ & .19 & .31 & $-.12^{* * *}$ & .33 & .42 & $-.09^{* * *}$
\end{tabular}

Height for Age (HAZ)

\begin{tabular}{|c|c|c|c|c|c|c|}
\hline Severe $(<-3)$ & .40 & .34 & .06 & .33 & .22 & $.11^{* * *}$ \\
\hline Moderate $(-3$ to -2$)$ & .19 & .15 & .04 & .20 & .23 & -.03 \\
\hline $\operatorname{Mild}(-2$ to -1$)$ & .17 & .18 & -.01 & .19 & .25 & $-.06^{* *}$ \\
\hline $\operatorname{Normal}(>-1)$ & .24 & .32 & $-.08 * *$ & .27 & .30 & -.03 \\
\hline & \multicolumn{6}{|c|}{ Girls } \\
\hline Weight for Age (WAZ) & \multicolumn{3}{|c|}{6 mths -3 years } & \multicolumn{3}{|c|}{$3-10$ years } \\
\hline Severe $(<-3)$ & .36 & .24 & $.12^{* * *}$ & .22 & .16 & $.06^{* *}$ \\
\hline Moderate $(-3$ to -2$)$ & .21 & .20 & .01 & .20 & .22 & .00 \\
\hline $\operatorname{Mild}(-2$ to -1$)$ & .20 & .31 & $-.11^{* * *}$ & .26 & .23 & -.03 \\
\hline $\operatorname{Normal}(>-1)$ & .22 & .24 & -.02 & .32 & .39 & $-.07^{* *}$ \\
\hline \multicolumn{7}{|l|}{ Height for Age (HAZ) } \\
\hline Severe $(<-3)$ & .42 & .33 & $.09 * *$ & .33 & .26 & $.08^{* * *}$ \\
\hline Moderate $(-3$ to -2$)$ & .21 & .21 & .00 & .19 & .19 & -.00 \\
\hline $\operatorname{Mild}(-2$ to -1$)$ & .14 & .17 & .03 & .18 & .22 & $-.04^{*}$ \\
\hline $\operatorname{Normal}(>-1)$ & .22 & .28 & -.06 & .30 & .33 & -.03 \\
\hline
\end{tabular}


Table 5: Height for Age Results by Child Gender and Age Group: Children 7-120 months

\begin{tabular}{|c|c|c|c|c|c|c|c|}
\hline & (1) & $(2)^{a}$ & (3) & $(4)$ & (5) & $(6)^{a}$ & $(7)^{\mathbf{b}}$ \\
\hline & OLS & IV & IV & IV-TFE & IV-VFE & IV-TFE & IV-TFE \\
\hline Migrant Household (MH) & $\begin{array}{c}0.42^{\star \star \star} \\
{[0.12]}\end{array}$ & $\begin{array}{c}1.25^{\star \star \star} \\
{[0.45]}\end{array}$ & $\begin{array}{c}1.25^{\star \star \star} \\
{[0.47]}\end{array}$ & $\begin{array}{c}1.45^{\star \star \star} \\
{[0.49]}\end{array}$ & $\begin{array}{c}1.84^{\star \star \star} \\
{[0.55]}\end{array}$ & $\begin{array}{l}1.81^{\star \star} \\
{[0.91]}\end{array}$ & $\begin{array}{c}1.66^{\star \star \star} \\
{[0.52]}\end{array}$ \\
\hline Migrant HouseholdBoy & $\begin{array}{l}-0.12 \\
{[0.14]}\end{array}$ & $\begin{array}{c}0.15 \\
{[0.39]}\end{array}$ & $\begin{array}{c}0.15 \\
{[0.39]}\end{array}$ & $\begin{array}{c}-0.98^{\star \star *} \\
{[0.38]}\end{array}$ & $\begin{array}{l}-0.70^{\star} \\
{[0.36]}\end{array}$ & $\begin{array}{l}-1.45^{\star *} \\
{[0.72]}\end{array}$ & $\begin{array}{c}-0.93^{\star *} \\
{[0.43]}\end{array}$ \\
\hline Boy & $\begin{array}{c}0.06 \\
{[0.07]}\end{array}$ & $\begin{array}{c}0.00 \\
{[0.12]}\end{array}$ & $\begin{array}{c}0.00 \\
{[0.12]}\end{array}$ & $\begin{array}{c}0.33^{\star \star \star} \\
{[0.12]}\end{array}$ & $\begin{array}{l}0.25^{\star \star} \\
{[0.11]}\end{array}$ & $\begin{array}{l}0.43^{*} \\
{[0.25]}\end{array}$ & $\begin{array}{l}0.31^{\star *} \\
{[0.13]}\end{array}$ \\
\hline Number of Adult Males & & & $\begin{array}{c}0.01 \\
{[0.06]}\end{array}$ & & & & \\
\hline Test of IV relevance & & 538.85 & 503.91 & 169.3 & 120.95 & 45.36 & 124.5 \\
\hline Over Id. Test $\chi_{2} p$-value & & & & .08 & .36 & .09 & .29 \\
\hline Sample Size & 4248 & 4193 & 4193 & 4193 & 4192 & 1059 & 3183 \\
\hline$F$ for $\mathrm{MH}$ (No. of inst.) & & $29.9(2)$ & $26.8(2)$ & $45.4(4)$ & $32.7(4)$ & $11.7(4)$ & $31.9(4)$ \\
\hline$F$ for $\mathrm{MH}^{\star} \mathrm{Boy}$ (No. of inst.) & & $34.9(2)$ & $35.7(2)$ & $90.9(4)$ & $78.9(4)$ & $35.6(4)$ & $88.4(4)$ \\
\hline Tehsil Fixed Effect & No & No & No & Yes & & Yes & Yes \\
\hline Village Fixed Effects(142) & No & No & No & & Yes & & \\
\hline \multicolumn{8}{|c|}{ 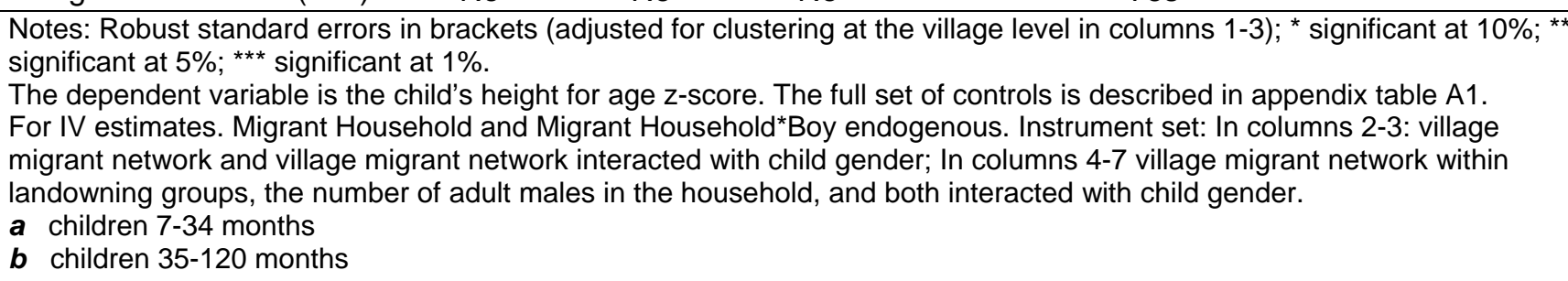 } \\
\hline
\end{tabular}




\begin{tabular}{|c|c|c|c|c|c|}
\hline & (1) & $(2)$ & (3) & (4) & $(5)$ \\
\hline & OLS & IV & IV & IV-TFE & IV-VFE \\
\hline Migrant Household (MH) & $\begin{array}{c}0.27^{\star \star \star} \\
{[0.09]}\end{array}$ & $\begin{array}{c}1.02^{\star \star \star} \\
{[0.29]}\end{array}$ & $\begin{array}{c}1.04^{\star \star \star} \\
{[0.30]}\end{array}$ & $\begin{array}{l}0.73^{\star \star} \\
{[0.37]}\end{array}$ & $\begin{array}{c}1.21^{\star \star \star} \\
{[0.43]}\end{array}$ \\
\hline Migrant HouseholdBoy & $\begin{array}{c}0.02 \\
{[0.11]}\end{array}$ & $\begin{array}{l}-0.14 \\
{[0.24]}\end{array}$ & $\begin{array}{l}-0.09 \\
{[0.23]}\end{array}$ & $\begin{array}{c}-0.68^{\star \star} \\
{[0.30]}\end{array}$ & $\begin{array}{c}-0.57^{\star *} \\
{[0.29]}\end{array}$ \\
\hline Boy & $\begin{array}{c}0.05 \\
{[0.06]}\end{array}$ & $\begin{array}{c}0.1 \\
{[0.09]}\end{array}$ & $\begin{array}{c}0.09 \\
{[0.09]}\end{array}$ & $\begin{array}{l}0.24^{\star *} \\
{[0.09]}\end{array}$ & $\begin{array}{l}0.23^{* *} \\
{[0.10]}\end{array}$ \\
\hline Number of Adult Males & & & $\left.\begin{array}{c}0 \\
{[0.04]}\end{array}\right]$ & & \\
\hline Test of IV relevance & & 558.1 & 529.6 & 175.8 & 125.1 \\
\hline Over Id. Test $\chi_{2} p$-value & & & & .16 & .15 \\
\hline Sample Size & 4395 & 4338 & 4368 & 4338 & 4396 \\
\hline$F$ for $\mathrm{MH}$ (No. of inst.) & & $30.2(2)$ & 27.9 & $46.6(4)$ & $34.1(4)$ \\
\hline$F$ for $\mathrm{MH}^{\star}$ Boy (No. of inst.) & & $33.9(2)$ & 36.5 & $94.1(4)$ & $83.9(4)$ \\
\hline Tehsil Fixed Effects & No & No & No & Yes & \\
\hline Village Fixed Effects & No & No & No & & Yes \\
\hline \multicolumn{6}{|c|}{ 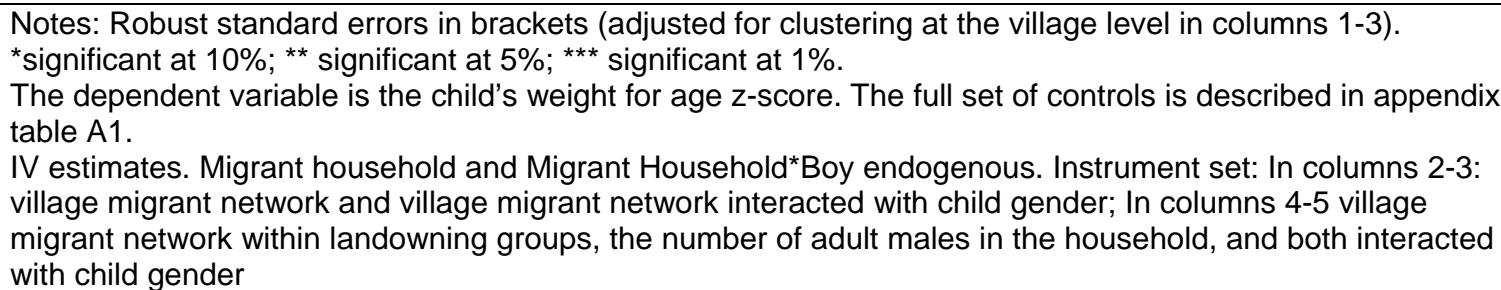 } \\
\hline
\end{tabular}


Table 7: Comparing Height for Age Z-scores for Siblings in Migrant Households: Children 24-120 months

\begin{tabular}{|c|c|c|c|}
\hline & $(1)$ & (2) & $(3)$ \\
\hline & Girls & Boys & Pooled \\
\hline \multirow[t]{2}{*}{ Born Before Migration } & $-1.05^{\star *}$ & 0.06 & 0.43 \\
\hline & {$[0.50]$} & {$[0.68]$} & {$[0.41]$} \\
\hline \multirow[t]{2}{*}{ Born Before Migration*Girl } & & & $-1.09 * *$ \\
\hline & & & [0.43] \\
\hline \multirow[t]{2}{*}{ Girl } & & & $1.04^{\star \star \star}$ \\
\hline & & & {$[0.38]$} \\
\hline Sample Size & 236 & 209 & 445 \\
\hline Number of households & 135 & 136 & 189 \\
\hline Sample contributing to the HFE & 32 & 43 & 113 \\
\hline Household Fixed Effects & Yes & Yes & Yes \\
\hline \multicolumn{4}{|c|}{$\begin{array}{l}\text { Notes: Robust standard errors in brackets; significant at } 10 \% \text {; }{ }^{* *} \text { significant at } 5 \% \text {; } \\
\text { significant at } 1 \% \text {. } \\
\text { The dependent variable is as described in table } 5 \text {. All specifications include controls for }\end{array}$} \\
\hline
\end{tabular}




\section{Appendix}

\begin{tabular}{|c|c|c|c|c|}
\hline \multirow[t]{2}{*}{ Table A1: Descriptive Statistics } & \multicolumn{4}{|c|}{ Child and Household Characteristics (Table 5 and 6 ) } \\
\hline & $(1)$ & $(2)$ & (3) & $(4)$ \\
\hline & $\begin{array}{c}\text { Mean } \\
\text { (St. Dev.) }\end{array}$ & HAZ & WAZ & Migration \\
\hline \multirow{2}{*}{ Age (months) } & 61.81 & 0.00 & $0.01^{\star \star \star}$ & 0.00 \\
\hline & $(32.24)$ & {$[0.00]$} & {$[0.00]$} & {$[0.00]$} \\
\hline \multirow[t]{2}{*}{ Age2 } & 4859.54 & 0.00 & $-0.00 * \star$ & 0.00 \\
\hline & $(4166.43)$ & {$[0.00]$} & {$[0.00]$} & {$[0.00]$} \\
\hline \multirow[t]{2}{*}{ Mother's Height } & 152.06 & $0.03^{* * *}$ & $0.01^{\star \star \star *}$ & 0.00 \\
\hline & (6.93) & {$[0.01]$} & {$[0.00]$} & {$[0.00]$} \\
\hline \multirow[t]{2}{*}{ Mother's Education } & .59 & $0.05^{\star \star \star}$ & $0.06^{\star \star \star}$ & 0.00 \\
\hline & $(2.07)$ & {$[0.02]$} & {$[0.01]$} & {$[0.00]$} \\
\hline \multirow[t]{2}{*}{ Mother's Age } & 32.11 & $0.02^{* \star *}$ & $0.01^{\star *}$ & 0.00 \\
\hline & (8.08) & {$[0.01]$} & {$[0.01]$} & {$[0.00]$} \\
\hline \multirow[t]{2}{*}{ Father's Education } & 3.59 & 0.01 & 0.00 & 0.00 \\
\hline & $(4.59)$ & {$[0.01]$} & {$[0.01]$} & {$[0.00]$} \\
\hline \multirow[t]{2}{*}{ Father's Age } & 38.04 & -0.01 & 0.00 & 0.00 \\
\hline & $(9.83)$ & {$[0.00]$} & {$[0.00]$} & {$[0.00]$} \\
\hline \multirow[t]{2}{*}{ Older Boy less than 18} & .74 & -0.02 & $-0.15^{\star \star}$ & -0.01 \\
\hline & $(.44)$ & {$[0.08]$} & [0.06] & {$[0.01]$} \\
\hline \multirow[t]{2}{*}{ Older Girl less than 18} & .73 & $-0.22^{\star \star \star}$ & $-0.21^{* \star *}$ & $0.02^{*}$ \\
\hline & $(.44)$ & {$[0.08]$} & {$[0.06]$} & {$[0.01]$} \\
\hline \multirow[t]{2}{*}{ Total Siblings } & 2.78 & 0.01 & 0.03 & 0.00 \\
\hline & $(1.66)$ & {$[0.03]$} & {$[0.02]$} & {$[0.00]$} \\
\hline \multirow[t]{2}{*}{ Grandmother in house } & .22 & $0.44^{\star \star \star}$ & $0.34^{\star \star \star}$ & -0.04 \\
\hline & $(.41)$ & {$[0.15]$} & {$[0.13]$} & [0.03] \\
\hline \multirow[t]{2}{*}{ Grandfather in house } & .26 & $-0.50 * * \star$ & $-0.30 * *$ & -0.02 \\
\hline & $(.44)$ & [0.15] & [0.13] & {$[0.03]$} \\
\hline \multirow[t]{2}{*}{ Indicator for Joint Family } & .44 & 0.13 & 0.09 & $-0.03^{\star}$ \\
\hline & $(.50)$ & {$[0.09]$} & {$[0.07]$} & {$[0.02]$} \\
\hline \multirow[t]{2}{*}{ Dependency Ratio } & 1.53 & $0.13^{\star \star}$ & 0.06 & $-0.04^{\star \star \star}$ \\
\hline & $(.87)$ & {$[0.06]$} & {$[0.05]$} & {$[0.01]$} \\
\hline \multirow[t]{2}{*}{ Inherited Land (in Acres) } & 3.17 & 0.00 & 0.00 & $-0.00^{\star \star *}$ \\
\hline & (10.73) & {$[0.00]$} & {$[0.00]$} & {$[0.00]$} \\
\hline \multirow[t]{2}{*}{ Migrant Network by Land (MNL) } & .16 & & & $0.31^{\star \star \star}$ \\
\hline & $(.21)$ & & & {$[0.04]$} \\
\hline \multirow[t]{2}{*}{ No. Adult Males (NAM) } & 2.05 & & & $0.06^{\star \star \star}$ \\
\hline & $(1.46)$ & & & {$[0.01]$} \\
\hline \multirow[t]{2}{*}{ MNL*NAM* Boy } & .18 & & & $0.04^{\star \star \star}$ \\
\hline & $(.54)$ & & & {$[0.01]$} \\
\hline \multirow[t]{2}{*}{ NAM*Boy } & 1.00 & & & -0.01 \\
\hline & $(1.42)$ & & & {$[0.01]$} \\
\hline Tehsil Fixed Effects & 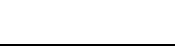 & Yes & Yes & Yes \\
\hline
\end{tabular}

